\title{
A PROBLEMÁTICA PÓS-MODERNA PARA A EDUCAÇÃO E O NEOLIBERALISMO
}

GOERGEN, Pedro. Pós-modernidade, ética e educação. 2. ed. Campinas: Autores Associados, 2001.

Jeronimo de Oliveira Lombardo*

A modernidade é, sem dúvida, um dos períodos mais instigantes da História. E isso decorre não por estar temporalmente perto de nós, mas em função das rápidas transformações realizadas e vivenciadas pela humanidade em curto espaço de tempo.

Muitos pensadores se debruçaram sobre os problemas inerentes à modernidade, alguns defendem a legitimidade do projeto moderno, outros, contudo, apresentam uma total descrença. Em suma, é próprio do pensamento contemporâneo ter por objeto de crítica o mundo construído pela modernidade, de maneira a estar nas bases do edifício moderno o princípio explicativo para a compreensão das crises éticas, políticas e educacionais atuais.

Em seu livro, Pedro Goergen problematiza os valores construídos pela modernidade, de modo que vão ao encontro dos debates éticos da contemporaneidade. Para tal, o autor evoca uma série de pensadores dos diversos períodos e escolas filosóficas, principalmente dos sécs. XIX e XX. Na introdução, Goergen fornece-nos o panorama e o objeto da sua análise.

Por um lado, suscita autores que suspeitaram do advento moderno: Max Weber, Nietzsche, Heidegger, Adorno, Horkheimer e Foucault. De outro, filósofos que assumiram o fracasso do projeto moderno, mas que acreditaram no emergir de uma nova era: a pós-modernidade, dos quais se podem mencionar Lyotard e Vattimo. O principal debate do livro ocorre entre os pensadores tidos por pós-modernos e Habermas, sendo este filósofo advindo da famigerada Escola de Frankfurt e notoriamente conhecido pela Teoria do Agir Comunicativo.

Segundo Goergen, os pós-modernos apregoam o "surgimento de uma nova consciência" (2001, p. 6), algo que o autor insiste em repetir três vezes ou mais no texto introdutório. A "nova consciência" deve repensar o sentido da vida e existência humanas. $\mathrm{O}$ texto, nesse momento, transmite-nos a impressão de um certo otimismo em

\footnotetext{
* Licenciado em Filosofia e graduando em Pedagogia pelo Centro Universitário Assunção - UNIFAI.
} 
relação ao caos vivido pela humanidade, isto é, as guerras mundiais. É de praxe o surgimento de sentimentos otimistas após catástrofes.

O conjunto de problemas inerentes do mundo moderno é enfatizado pelo autor: o embate e a contraposição, próprios das discussões éticas, entre o indivíduo e a coletividade; a emancipação humana através do domínio e do aprimoramento técnicocientífico; a substituição das narrativas teocêntricas pelas antropocêntricas; o avanço do capitalismo e da economia liberal etc. Todas as questões abordadas procuram entender o fenômeno ético sob o prisma do processo educativo.

No primeiro capítulo, Goergen apresenta um panorama da nova configuração do mundo e a negação da modernidade, isto é, a transição da visão de mundo teocêntrica para a lógica do mundo empreendida pela modernidade, de caráter antropocêntrico. Se no teocentrismo, o homem desejava e esperava o tempo vindouro (o céu, o reino de Deus etc.), na concepção antropocentrista, a única certeza se encontra no momento presente. Uma vez liberto das amarras do transcendente, deixando de ser menor, o homem tornou-se dono do próprio destino ao perceber que não haveria limites para as empreitadas da razão. A natureza dessacralizada, a partir do mundo moderno, passou a ser instrumentalizada para a resolução do problemas e necessidades humanas.

Vários filósofos que contribuíram para a formação do pensamento moderno, do Renascimento ao Iluminismo, são apontados: Descartes, Petrarca, Roger Bacon, Copérnico, Francis Bacon, Newton, Kant etc. O espírito moderno atingiu o seu cume principalmente com o criticismo kantiano, o qual colocou "a pá de cal" no pensamento metafísico e postulou a confiança total na razão. Na concepção pós-moderna, a ilimitada confiança e suficiência da razão humana foi o motivo da dissolução dos metarrelatos ou das metanarrativas (GOERGEN, 2001, p. 13).

$\mathrm{Na}$ busca e na crença de um futuro melhor e "feliz", a humanidade passou a intensificar o processo de dominação do mundo, assim, a fé incondicional na razão, centrada no próprio sujeito cognoscente, permitiu ao homem acentuar a individualidade. Por meio da ideia de progresso secular, acredita-se, principalmente na concepção positivista, que a humanidade passara por estágios, sendo o estágio atual superior aos anteriores.

O ápice do processo moderno, a Revolução Francesa, cujo auge se deu em 1789, significou o rompimento voraz da lógica do passado. $\mathrm{O}$ homem, não entregue à divindade, tornou-se autor da própria história e condutor do Estado democrático. Por excelência, o humano é o único ser histórico, nem Deus nem natureza possuem 
historicidade, de modo que o primeiro - Deus - possivelmente existente, estaria fora do tempo e do espaço; e a segunda - a natureza - nada registra, simplesmente é. Por limitar as possibilidades da existência de outro mundo, o próprio humano é o meio e o fim, a felicidade só pode ser alcançada neste mundo.

As Revoluções liberais ou burguesas, a Francesa e Industrial, revelaram-se a quebra dos fundamentos medievais-feudais, de forma que preconizaram os ideais sociais e morais, alicerçando as bases do Estado moderno-contemporâneo; modificaram drasticamente o modo de produção e as relações produtivas, intrinsecamente sociais, segundo Marx.

Apesar de o autor abordar a substituição das concepções e configurações de mundo por outro, é interessante notar que, na verdade, tudo não se tratou de um engodo; as mudanças só ocorreram superficialmente, uma vez que repetiu a mesma lógica que fora reprimida.

Por vezes, Goergen é repetitivo nos dados. O presente autor demonstrou-se intelectualmente honesto, justificando os limites do próprio texto ao apresentar os vorazes críticos da razão moderna, de maneira a exibir as teorias, com grande envergadura teórico-intelectual, em um curto espaço.

Os principais negadores da razão moderna, no parecer do autor, são: Nietzsche, Heidegger, Adorno e Horkheimer, sendo os dois últimos da Escola de Frankfurt. Talvez pelo pouco espaço, limitou-se a apresentar somente as críticas de Adorno e Horkheimer, carecendo também referências ao surgimento das ciências (compartimentadas) no séc. XIX, o pensamento de Freud (psicologia social) e as contribuições de Marx.

Na concepção weberiana, "A modernidade é o processo de desencantamento da organização religiosa do mundo.” (GOERGEN, 2001, p. 16). Nesse sentido, a obra mais famosa, dos frankfurtianos Adorno e Horkheimer, a Dialética do Esclarecimento ou do Iluminismo, denuncia o fracasso do programa moderno. $\mathrm{O}$ saber humano, que o torna superior em relação aos demais seres, é, antes de tudo, utilizado para instrumentalizar o mundo e os próprios homens. Em nome do progresso, o ser humano sacrifica-se a si mesmo.

A própria subjetividade humana é construída e programada para que se deseje os fins da classe dominante. A razão instrumentalizada busca maior eficiência econômica e administrativa (GOERGEN, 2001, p. 20), ou seja, o próprio humano deve moldar-se às regras gerais impostas pelo sistema econômico, no caso, o Capitalismo. O saber técnico, poder do homem perante a natureza, visa ao prático, porém desprovido da dimensão 
intelectiva e crítica. Na lógica da técnica, o homem é coisa passível de substituição, ademais, o mesmo não consegue enxergar-se dominado, de maneira a própria subjetividade ser objetivada. Os detentores da técnica sempre são os mesmos que almejam e que possuem o poder político, uma vez que precisam assegurar o processo de dominação.

No capítulo segundo, contexto dos "pós-modernos", para Goergen, as teses centrais, debatidas entre os autores desta orientação filosófica, concernem no processo educativo da contemporaneidade, o qual está permeado no dualismo teoria-práxis. O debate dos pós-modernos está envolto da tese central: do fim da história ou do fim dos metarrelatos.

Segundo os pós-modernos apresentados, principalmente Lyotard e Vattimo, a modernidade não se realizou, de modo a ser um projeto destruído e liquidado. Houve o fracasso do projeto emancipador do Iluminismo, o auge da racionalidade. A condição pós-moderna não aceita e nem acredita nas metanarrativas, pois esvaeceram-se todas as esperanças e crenças no projeto moderno.

Há uma certa dose de conformismo, especialmente em Fukuyama, o qual acredita que o "fim da história" está marcado pelo término da Guerra Fria, isto é, pela queda do muro de Berlim (1989), sendo o Capitalismo o único sistema possível.

Diferentemente dos pós-modernos, Habermas prisma pela intersubjetividade e a universalidade, sendo isto um sinônimo da sua Teoria do Agir Comunicativo. Apesar de crítico da modernidade, ao contrário de Lyotard e dos defensores do fim da história, Habermas, de certa maneira, advoga em favor da razão moderna.

Para ele, o fracasso do processo emancipatório não o torna inválido. O filósofo alemão critica os posicionamentos da pós-modernidade, visto que a própria está inserida no contexto moderno, e despreza, sobretudo, a tentativa conservadora dos pós-modernos de se colocarem neutros no processo. Eles estão de algum modo inseridos, não existe "fim da história", o que representaria a desistorização do humano, o findar da humanidade. Um metarrelato só pode ser destruído por outro equivalente; não percebem, os pós-modernos, que estão no fluxo do projeto moderno.

Lyotard critica a crença iluminista na razão como universal e na concepção teleológica (finalista, necessária) da história. Vários exemplos históricos, do séc. XX, como no caso de Auschwitz, são utilizados para comprovar o descrédito e a ruína do projeto moderno. 
Segundo Vattimo, igualmente pós-moderno, a modernidade recupera e legitima o pensamento metafísico e, divergentemente, a pós-modernidade explicita os pressupostos da legitimação moderna.

Outro crítico da pós-modernidade, além de Habermas, é Rorty. Para ele, a pósmodernidade é o fim da história, uma vez que a própria história é invenção metafísica, portanto, com a extinção da metafísica, também se extinguem suas leis na compreensão do mundo.

A comparação realizada por Goergen, entre os pós-modernos, demonstra as divergências conceituais entre os pares teóricos. Assim, como em outros movimentos do pensamento humano, não há um consenso na corrente teorética pós-moderna. Contudo, vale-nos ressaltar que, apesar de serem denominados pós-modernos, não se autodefinem deste modo.

Para o autor, os problemas mais importantes do debate contemporâneo são a concepção pós-moderna de um pretenso "fím da história" e o esgotamento da racionalidade moderna. São inegáveis as profundas marcas da modernidade na modificação e na formação do mundo contemporâneo, tendo principalmente implicações no mundo epistêmico, sobretudo no que se refere às garantias humanas de orientar os rumos da história, coletiva e individual. Goergen defende a todo instante a necessidade de postular novas utopias, novos sonhos e novos ideais. No horizonte ético e educacional emerge a pergunta: o que norteará a ação humana sem os pressupostos metafísicos? A resposta a esta pergunta é incansavelmente perseguida pelo autor.

A principal discussão ocorre no capítulo terceiro, o cume do livro que é intitulado “tempos de pós-moralidade?”. Ali, são enfatizadas as posições de Habermas versus as de Lipovetsky, pós-moderno. Enquanto a concepção habersiana defende a intersubjetividade, a de Lipovetsky apregoa o “individualismo responsável”. Goergen adverte, ao leitor, a caracterização genérica da exposição dos referidos autores.

Em sua Teoria da Ação Comunicativa, Habermas aborda, por meio da esfera da prática e do discurso, as questões da convivência humana. Para ele, o discurso sobre a prática incide no agir comunicativo, procurando recuperar a consciência do indivíduo sobre a práxis em relação ao discurso. Possui por tentativa superar o modelo filosófico da subjetividade, próprio da modernidade, para a intersubjetividade (GOERGEN, 2001, p. 40), em razão de a verdade estar alicerçada na relação, entre indivíduo e coletividade.

O agir prático é fundamentado entre os indivíduos por meio das normativas morais convencionais, em suma, um acordo coletivo. Por isso, a ética do discurso de 
Habermas é definida por dois pressupostos inseparáveis: uma teoria moral fundamentada na linguagem $\mathrm{Na}$ compreensão de Habermas, a moral depende da linguagem na medida em que as convenções morais entre os indivíduos perpassam pelo discurso, que por sua vez é tanto teórico quanto prático.

O filósofo alemão postula dois tipos de ações: a ação instrumental e a ação comunicativa. Sendo um fator predominante na modernidade, inclusive amplamente investigada por Weber e os frankfurtianos, a ação instrumental visa a técnica como meio para alcançar determinados fins em um mundo permeado por sistemas, o mundo sistêmico. A linguagem é substituída com êxito, principalmente na transposição da linguagem econômica pelo dinheiro e a linguagem política pelo poder. Já a ação comunicativa, ao considerar o mundo da vida, possui por horizonte o entendimento (indivíduo) e o espaço social (coletivo), nos quais se legitimam as normativas morais e as leis éticas.

Apesar de os dois mundos, o sistêmico e o da vida, complementarem-se, ambos estão se desmembrando. O problema reside, segundo Habermas, no absorver do mundo sistêmico ao mundo da vida, tornando-o complexo por meio da instrumentalização dos valores.

Ao assumir o caráter pragmático da linguagem, Habermas consegue formular uma teoria "consensual" - aprovação majoritária da verdade, do agir moral e da ética discursiva (GOERGEN, 2001, p. 43). O sujeito se constrói por mediação da comunicação, sendo assim, a verdade só é firmada por meio do procedimento discursivo com implicações válidas.

Duas são as frentes e formas discursivas na concepção de Habermas: a prática, a qual examina as pretensões da validade das normas e de um sistema normativo, possuindo um exame crítico em relação a elas, isto é, perpassando por um processo argumentativo; e o teórico, que procura provar ou refutar a verdade das proposições factuais e que ambiciona o estatuto científico, ou seja, como teoria procura por critérios para a verdade.

A razão comunicativa incide no discurso dialógico entre a teoria-prática. É intersubjetiva pois não possui o primado no sujeito cognoscente, mas porque a razão comunicativa, proposta por Habermas, está centrada no grupo, sendo um processo dialógico, racional e democrático.

Pós-moderno, Lipovetsky acusa Habermas de elitista e de intelectualista na medida em que este postula o uso crítico da razão, recaindo no mesmo erro da 
modernidade. O pensador francês defende o consumo midiático, uma vez que o ato de consumir não anula a razão. A vontade individual, de índole mais imediata e menos teórica, é suprema. Não é o discurso que tirará a humanidade da crise ética, mas, antes, a própria vida prática.

A própria noção de "ética" é massificada, ademais, o próprio termo "ética" é difundido de forma errônea. Para além do dogmatismo ético e das normatizações do direito, a ética é um "campo minado" dos conflitos entre as singularidades e as pluralidades, contudo, há a necessidade da fixação de limites para a preservação da vida humana.

A inteligência pragmática, em busca de valores democráticos, não representa o suporte permanente do bom andamento das instituições e das relações humanas (GOERGEN, 2001, p. 51), mas somente com o investimento dos recursos de empresas e políticas que estimulem a movimentação das mentes humanas para a responsabilidade social. Lipovetsky salvaguarda uma ética laica e universal na qual o indivíduo possui o primado no padrão moral.

O filósofo critica as éticas que justificam o sacrifício próprio em nome do dever (ou deontológicas, encontradas principalmente em pensadores como Kant, Bentham e Stuart Mill). Para o francês, a ética está em constante relação aos valores individualistas calcados no prazer. Defende que a cultura pós-moralista, midiática, surgiu através da administração coletiva das individualidades, com fins comerciais, e que jamais deveria preocupar-se com o "justo" ou "injusto", com o "certo" ou "errado", tal como no parecer das éticas remotas (Platão, Agostinho, Kant etc.).

$\mathrm{Na}$ nova era individualista, segundo Lipovetsky, os direitos reclamados são subjetivos, ao contrário da moral ideal que abnega o indivíduo ao colocar o dever acima do direito. O predomínio do direito subjetivo, incentivado pelo consumo, já é vivenciado pela cultura de massas, é um fato dado.

Diante da realidade midiática, não é mais possível recorrer aos fundamentos metafísicos ou teológicos, entretanto, objeta Goergen, quais seriam as bases éticas desprovidas de uma metafísica? Parece-nos impensável uma ética não metafísica.

No quarto capítulo, "novas perspectivas para a educação", o autor destina as reflexões para o campo educacional por meio de uma filosofia teórica, de cunho epistêmico, e de uma filosofia prática, de cunho ético. Desenvolve as problematizações anteriores a partir do próprio ponto de vista, recuperando, de certa forma, a dimensão histórica da educação que já fora abordada por outras chaves de leitura. 
Segundo Goergen, deve-se a pensar o Estado moderno para compreender a prática educativa contemporânea que, centrada nos conhecimentos cientificistas, salvaguarda resquícios de uma racionalidade emancipadora. A pedagogia (ciência da educação) dos Iluministas fora alicerçada nas mesmas bases epistemológicas das quais "abriram mão" para a confiança absoluta na razão. Com tendências universalizantes e de amplo acesso escolar, preconizavam que a razão é um meio de melhorar a natureza humana, isso em vista de uma sociedade mais justa, igualitária e democrática.

Os burgueses, os verdadeiros promotores das revoluções, de progressistas para conservadores, utilizaram a razão como forma de justificar e legitimar a dominação e os interesses da própria classe.

Goergen, em seu discurso, parte de dois prismas, ou melhor, expõe as suas reflexões por duas premissas. Questiona-se se ainda há legitimidade em amparar nas metanarrativas, de cunho teleológico, a prática educativa, das quais também se serviram os Iluministas e que demonstraram um engodo discursivo e social da legitimidade da razão. Em seguida, reflete, relacionando a ética e a educação. $\mathrm{O}$ autor assume as dificuldades impostas pelo período contemporâneo de apresentar conclusões, isso decorrente das complexidades do momento. E aponta críticas pontuais aos pósmodernos, visto que o discurso pós-moderno, apesar de tentar resolver a aporia contemporânea, está longe de solucionar ou de ter conclusões satisfatórias, dado ser um discurso contraditório devido à perda de um "sistema" de verdades.

Enterram, os pós-modernos, o discurso moderno no passado, esquecendo que este possui grande influência na vida social contemporânea, isto é, para o entendimento da situação educacional e da prática educativa atuais. Segundo Goergen, a tese do "fim da história" necessita de fundamentos, e se caso estiverem certos, representaria a ruptura na prática educativa e da tentativa de tornar a sociedade melhor. As dificuldades residem na falta de clareza de uma transição para uma nova ordem. Não há como permanecer em um "caminho sem saída", com passividades e resignação diante da realidade global.

Em face do processo educativo, vários são os problemas criados pela abordagem dos pós-modernos, principalmente o intento de paralisar as tentativas das transformações das realidades sociais. Ademais, o pensamento pós-moderno não se coloca dentro de um período, mas simplesmente como modelo de pensamento. Toda tentativa de fundamentação é acusada, pelos pós-modernos, de ideológica e totalitária, defendendo a tendência individualizante, a qual destrói as utopias das consciências 
coletivas, os pensamentos e lutas; beneficiam imperialismos, os quais fazem subalternos os países "emergentes" ou "em desenvolvimento", como é o caso da dominação ideológica e econômica imposta pelos Estados Unidos.

Goergen acredita que a educação possui por função a construção de um novo projeto social, portanto sempre carece de fundamentos. O principal questionamento do autor, no que se refere aos pós-modernos, é se realmente as críticas deles possuem legitimidade prática, visto que transcendem, sendo desistoricizantes.

Aparentemente constituem uma nova forma de domínio ao defenderem certa indiferença política, quando na verdade o problema é político. A abordagem pósmoderna, na defesa do mercado, omite as culturas e as etnias, fazendo ressurgir fundamentalismos e relativismos éticos; em um mundo globalizado há a tendência de uniformizar culturas e etnias, resguardando o controle da cultura como mercadoria selecionada para o consumo.

No sistema Capitalista é o capital quem dita as regras, sendo assim, não seria diferente no contexto educacional. Sociedades são engolidas pelo mercado através das desregulações dos Estados na economia e das medidas de privatização. Nesse contexto, como produto de consumo, a educação é mercadorizada ao se desmembrar do Estado, acentuando desigualdades; descaracteriza o humano nas fábricas educacionais.

A escola reformulada por uma nova organização do sistema de ensino, em defesa da exacerbação do indivíduo, desburocratiza o currículo e afrouxam as leis para possibilitar a escolha de qual produto levar.

Como é possível, pergunta Goergen, em meio à desordem e de natureza universalizante, o Capitalismo se impor? Ao atravessar da rigidez para a desconstrução das regras, como seria possível um fundamento para a prática educativa?

O autor é um crítico da modernidade, porém, também é severo em relação aos pós-modernos, de forma que seus pontos de vista ajudaram a aprofundar ainda mais a crise contemporânea. Como proposta de fugir do relativismo ético, a partir do diálogo, Goergen acredita na construção de novos princípios que orientem a práxis educativa, contudo não crê no retorno do passado metafísico.

A ética do discurso de Habermas, segundo o autor, possui maior relevo ao considerar os valores e a normas construídos pelas práticas humanas, que são históricas. O humano é ser de relação e nasce inserido em um contexto histórico-social. Sendo assim, a educação possui um papel sociocultural. É um processo de construção lento 
transmitido pelas gerações, que não é aleatório nem descartável. (GOERGEN, 2001, p.80).

A formação humana está além da esfera puramente individual, mas está intimamente relacionada ao coletivo, ao que, no prisma de Habermas, chama-se de Razão comunicativa, de traços universalizantes, superando o contexto cultural particular. Como está imbricada na prática, a educação não se restringe à formação institucional escolar, deve-se sempre reter a ideia da escola como responsável da constituição do "sujeito ético", na medida em que a formação do indivíduo é de caráter mais amplo.

São vários os problemas políticos e sociais que emperram projetos mais humanos e éticos, principalmente quando elites estão no poder, em detrimento aos que possuem menos capital econômico e político; visto que o valor transmitido pelo sistema é a competividade, a própria sociedade não se preocupa com a educação, desdenhando qualquer processo formativo para a solidariedade.

Por ser antagônica ao seu propósito, a escola tem por obrigação romper com a lógica mercadológica, ao invés de concordar, favorecendo reflexões inerentes ao real, sobretudo ao humano. Jamais deveria instrumentalizar os alunos em vista do sistema econômico, porém no intento de educar para compreender as diferenças através de atitudes dialógicas. Toda ética, como ciência, pressupõe certa racionalidade, em suma, a consciência do agir. O humano, ser em construção, não possui uma existência fixa assegurada, portanto, a escola deveria contribuir no processo da construção do humano, por conseguinte de uma sociedade melhor.

O texto de Goergen é de caráter aporético, ou seja, é inconclusivo assim como o sujeito da educação, o humano. Conjuntamente, com o homem, está a educação na marcha da História. O autor justifica, paradoxalmente, que concluiu uma obra inconclusiva, visto que também está inscrita dentro do processo. Não se findou a época debatida e abordada, assim como a prática e processo educativo.

De caráter repetitivo, na conclusão, Goergen demonstrou sumariamente o plano do que fora abordado em sua obra. Conclui que o homem é capaz de decidir o próprio destino e encontrar novos fundamentos para o pensar, para o agir e para a vida. (GOERGEN, 2001, p. 89). O humano deve, incessantemente, procurar algo no horizonte como referencial sobre si, a natureza e a sociedade. $\mathrm{O}$ autor assevera que enxerga com desconfiança o conformismo dos pós-modernos, e vê com mais proximidade a possibilidade da intersubjetividade propugnada por Habermas. 
A proposta do livro, em síntese, foi a de abordar como as questões epistemológicas, éticas e estéticas influenciam na vida humana, uma vez que estas dimensões representam o homem na sua integralidade. 